\title{
Hall Current and Joule Heating Effects on Flow of Couple Stress Fluid with Entropy Generation
}

\author{
Abiodun A. Opanuga \\ Department of Mathematics \\ Covenant University \\ Ota, Nigeria \\ abiodun.opanuga@covenantuiversity.edu.ng \\ Sheila A. Bishop \\ Department of Mathematics \\ Covenant University \\ Ota, Nigeria \\ sheila.bishop@covenantuiversity.edu.ng
}

\author{
Hilary I. Okagbue \\ Department of Mathematics \\ Covenant University \\ Ota, Nigeria \\ hilary.okagbue@covenantuiversity.edu.ng \\ Olasunmbo O. Agboola \\ Department of Mathematics \\ Covenant University \\ Ota, Nigeria \\ ola.agboola@covenantuiversity.edu.ng
}

\begin{abstract}
In this work, an analytical study of the effects of Hall current and Joule heating on the entropy generation rate of couple stress fluid is performed. It is assumed that the applied pressure gradient induces fluid motion. At constant velocity, hot fluid is injected at the lower wall and sucked off at the upper wall. The obtained equations governing the flow are transformed to dimensionless form and the resulting nonlinear coupled boundary value problems for velocity and temperature profiles are solved by Adomian decomposition method. Analytical expressions for fluid velocity and temperature are used to obtain the entropy generation and the irreversibility ratio. The effects of Hall current, Joule heating, suction/injection and magnetic field parameters are presented and discussed through graphs. It is found that Hall current enhances both primary and secondary velocities and entropy generation. It is also interesting that Joule heating raises fluid temperature and encourages entropy production. On the other hand Hartman number inhibits fluid motion while increase in suction/injection parameter leads to a shift in flow symmetry.
\end{abstract}

Keywords-Hall current; Joule heating; entropy generation; couple stress fluid; Adomian decomposition method

\section{INTRODUCTION}

The study of hydromagnetic flow has been extensively investigated in the past years due to its applications in MHD generators, flow control, shock damping in car absorbers, nuclear reactors, plasma studies, purifications of metal from non-metal enclosures, geothermal energy extractions, polymer technology and metallurgy. Relevant investigation was pioneered in the first half of the twentieth century. Thereafter several studies have been conducted. Author in [1] investigated the spontaneous magnetic field in a conducting liquid in turbulent motion. In [2], magnetohydrodynamics at high Hartmann numbers were investigated. Author in [3] considered the effect of a uniform magnetic field on the Eckman layer over an infinite horizontal plate at rest relative to an electrically conducting liquid rotating with uniform angular velocity about a vertical axis while authors in [4] analyzed the combined effect of free and forced convection on MHD flow in a rotating porous channel, authors in [5] investigated the radiation effect of magnetohydrodynamics flow of gas between concentric spheres. In [6], authors considered the radiative effect on velocity, magnetic and temperature fields of a magnetohydrodynamic oscillatory flow past a limiting surface with variable suction In [7], author considered the hydromagnetic natural convection flow between vertical parallel plates with time-periodic boundary conditions, Authors in [8] studied convection heat and mass transfer in a hydromagnetic flow of second grade fluid in the presence of thermal radiation and thermal diffusion. In the studies above where the effect of magnetic field is reported, small and moderate values of the magnetic field are assumed. However, the current trend of research is geared toward a strong magnetic field and a low density gas due to its numerous applications such as in space flight, nuclear fusion research, magnetohydrodynamic generators, refrigeration coils, electric transformers, Hall accelerators and biomedical engineering (e.g. cardiac MRI and ECG). Hall current occurs when the applied magnetic field is very strong or gas is ionized with low density leading to a reduction in conductivity normal to the magnetic field, as a result of the free spiraling of electrons and ions around the magnetic lines of force before collisions. This then induces a current in the direction of both electric and magnetic fields. This is referred to as Hall effect, the induced current is called Hall current [9-15].

In this study, the Hall current and Joule heating effects on the flow of couple stress fluid with entropy generation is considered. The study is essential due to the fact that entropy generation occurs in moving fluid with high temperature which can lead to loss of resources and effort if the inherent irreversibility in the fluid flow is not well addressed. Authors in 
[16] submitted that all processes that produce, convert and consume energy must be re-examined very carefully and all available-work destruction mechanisms must be removed. To the best of our knowledge similar study has not yet been reported in literature, although various factors responsible for the entropy production have been studied, for instance in [17] authors considered effects of velocity slip and temperature jump on the entropy generation in MHD flow over a porous rotating disk. Also, authors in [18] presented entropy generation on MHD nanofluid blood flow due to peristaltic waves. Recently, authors in [19] studied the thermodynamic analysis of hydromagnetic third grade fluid flow through a channel filled with porous medium. In [20], the effect of thermal radiation on the entropy generation of hydromagnetic flow through porous channel was investigated. More studies on the factors responsible for entropy production are reported in [21-26]. Several techniques such as Homotopy perturbation [27], differential transform method [28-29], variational iteration technique [30], finite difference technique [31] etc. are available in literature. However, the Adomian decomposition method is applied in this work due to its simplicity in application and rapid convergence, (see Tables I and II). Furthermore, the method has been used to analyze various linear and nonlinear problems such as the fractional-order differential equations [32], the time dependent Edem-Fowler type equation [33], the Navier-Stokes equations [34], the evolution model [35], the Flierl-Petviashivili equation [36], the fourth-order wave equation [37], the peristaltic transport model [38], the Fokker-Planck equation [39] and the Bratu's problem [40].

\section{PROBLEM FORMULATION}

Fully developed, steady, incompressible and electrically conducting couple stress fluid between two parallel plates of distance $h$ apart has been investigated. The coordinate system is taken such that the $\mathrm{x}$-axis is along the lower plate in the flow direction, the y-axis is normal to the xy-plane while $z$-axis is made perpendicular to the plates. A constant pressure gradient is induced along the x-direction. Hot fluid is injected into the channel wall at the lower plate and sucked off at the upper plate with the same velocity. Following [41], the generalized Ohm's law with Hall current is

$$
J+\frac{\omega_{e} \tau_{e}}{B_{0}}(J \times B)=\sigma(E \times q \times B)
$$

It is further assumed that if $\left(j_{x}, j_{y}, j_{z}\right)$ are the components of the current density $J$, the equations of conservation of electric charge $\nabla \cdot J=0$ shows that $j_{z}$ is constant which is assumed to be zero because $j_{z}=0$ at the plates which are electrically nonconducting. It then implies that $j_{z}=0$, everywhere in the flow. Furthermore, the electrical field $E=0$ [42]. Following the given assumptions, (1) becomes:

$$
\begin{aligned}
& j_{x}+m j_{y}=\sigma w B_{0} \\
& j_{y}-m j_{x}=-\sigma u B_{0}
\end{aligned}
$$

Note that $m=\omega_{e} \tau_{e}$ represents the Hall parameter. Solving (2) and (3) for $j_{x}$ and $j_{y}$ gives:

$$
\begin{aligned}
& j_{x}=\frac{\sigma B_{0}}{1+m^{2}}(w+m u) \\
& j_{y}=\frac{\sigma B_{0}}{1+m^{2}}(m w-u)
\end{aligned}
$$

The governing equations for the flow following [43-44] are: Momentum equation along axis $\mathrm{x}$ :

$$
\begin{aligned}
& \rho v_{\circ} \frac{d u^{*}}{d y^{*}}=-\frac{d p}{d x}+\mu \frac{d^{2} u^{*}}{d y^{* 2}}-\eta \frac{d^{4} u^{*}}{d y^{* 4}}- \\
& \frac{M^{2}}{1+m^{2}}\left(u^{*}-m w^{*}\right) ; \\
& u^{*}(0)=\frac{d^{2} u^{*}}{d y^{* 2}}(0)=0=u^{*}(h)=\frac{d^{2} u^{*}}{d y^{* 2}}(h),
\end{aligned}
$$

Momentum equation along axis y:

$$
\begin{aligned}
& \rho v_{\circ} \frac{d w^{*}}{d y^{*}}=\mu \frac{d^{2} w^{*}}{d y^{* 2}}-\eta \frac{d^{4} w^{*}}{d y^{* 4}}-\frac{M^{2}}{1+m^{2}}\left(w^{*}+m u^{*}\right) ; \\
& w^{*}(0)=\frac{d^{2} w^{*}}{d y^{2}}(0)=0=w^{*}(h)=\frac{d^{2} w^{*}}{d y^{2}}(h),
\end{aligned}
$$

Energy equation:

$$
\begin{aligned}
& \rho c_{p} v_{0} \frac{d T^{*}}{d y^{*}}=k \frac{d^{2} T^{*}}{d y^{* 2}}+\mu\left[\left(\frac{d u^{*}}{d y^{*}}\right)^{2}+\left(\frac{d w^{*}}{d y^{*}}\right)^{2}\right]+ \\
& \eta\left[\left(\frac{d^{2} u^{*}}{d y^{* 2}}\right)^{2}+\left(\frac{d^{2} w^{*}}{d y^{* 2}}\right)^{2}\right]+\lambda \sigma B_{0}^{2}\left(w^{* 2}+u^{* 2}\right) ; \\
& T^{*}(0)=T^{*}(h)=0 .
\end{aligned}
$$

Introducing the following dimensionless variables,

$$
\begin{aligned}
& y=\frac{y^{*}}{h}, u=\frac{u^{*}}{v_{0}}, w=\frac{w^{*}}{v_{0}}, \theta=\frac{T^{*}-T_{0}}{T_{h}-T_{0}}, G=-\frac{h^{2}}{\mu v_{0}} \frac{d P}{d x} \\
& a=\mu \frac{h^{2}}{\eta}, v=\frac{\mu}{\rho}, \Omega=\frac{T_{h}-T_{0}}{T_{0}}, s=\frac{v_{0} h}{v},
\end{aligned}
$$

Equations (6), (7) yield the following dimensionless form;

$$
\begin{aligned}
& s \frac{d u}{d y}=G+\frac{d^{2} u}{d y^{2}}-\frac{1}{a^{2}} \frac{d^{4} u}{d y^{4}}-\frac{M^{2}}{1+m^{2}}(u-m w), \\
& u(0)=\frac{d^{2} u}{d y^{2}}(0)=0=u(1)=\frac{d^{2} u}{d y^{2}}(1), \\
& s \frac{d w}{d y}=\frac{d^{2} w}{d y^{2}}-\frac{1}{a^{2}} \frac{d^{4} w}{d y^{4}}-\frac{M^{2}}{1+m^{2}}(w+m u), \\
& w(0)=\frac{d^{2} w}{d y^{2}}(0)=0=w(1)=\frac{d^{2} w}{d y^{2}}(1) \\
& \frac{d^{2} \theta}{d y^{2}}=s p_{r} \frac{d \theta}{d y}-B r\left[\left(\frac{d u}{d y}\right)^{2}+\left(\frac{d w}{d y}\right)^{2}\right]+ \\
& \frac{B r}{a^{2}}\left(\left(\frac{d^{2} u}{d y^{2}}\right)^{2}+\left(\frac{d^{2} w}{d y^{2}}\right)^{2}\right)+\lambda J h\left(u^{2}+w^{2}\right) \\
& \theta(0)=0, \theta(1)=1 .
\end{aligned}
$$


where

$$
\begin{aligned}
& \operatorname{Pr}=\frac{v \rho c_{p}}{k}, B r=\frac{\mu v_{0}^{2}}{k\left(T_{h}-T_{\mathrm{o}}\right)}, N s=\frac{T_{\circ}^{2} h^{2} E_{G}}{k\left(T_{h}-T_{\mathrm{o}}\right)^{2}}, \\
& J h=B r M^{2}, M^{2}=\frac{\sigma B_{0}^{2} h^{2}}{\mu} .
\end{aligned}
$$

\section{ADOMIAN DECOMPOSITION}

The Adomian decomposition method is applied by writing (10), (11) and (12) in integral form as:

$$
\begin{aligned}
& u(y)=b_{1} y+\frac{b_{2}}{3 !} y^{3}- \\
& \int_{0}^{y} \int_{0}^{y} \int_{0}^{y} \int_{0}^{y}\left\{\begin{array}{l}
s \frac{d u}{d Y}-G-\frac{d^{2} u}{d Y^{2}}+ \\
\frac{M^{2}}{1+m^{2}}(u-m w)
\end{array}\right\} d Y d Y d Y d Y, \\
& w(y)=f_{1} y+\frac{f_{2}}{3 !} y^{3}- \\
& \int_{0}^{y} \int_{0}^{y} \int_{0}^{y} \int_{0}^{y}\left\{\begin{array}{l}
d w \\
s Y
\end{array}-\frac{d^{2} w}{d Y^{2}}+\frac{M^{2}}{1+m^{2}}(w+m u)\right\} d Y d Y d Y d Y,
\end{aligned}
$$

and

$$
\begin{aligned}
& \theta(y)=b_{3}+b_{4} y- \\
& \int_{0}^{y} \int_{0}^{y}\left\{\begin{array}{l}
s \operatorname{Pr} \frac{d \theta}{d y}-B r\left(\frac{d u}{d y}\right)^{2}+\left(\frac{d w}{d y}\right)^{2}+ \\
a^{2}\left(\left(\frac{d^{2} u}{d y^{2}}\right)^{2}+\left(\frac{d^{2} w}{d y^{2}}\right)^{2}\right)+ \\
\lambda J h\left(u^{2}+w^{2}\right)
\end{array}\right\} d Y d Y .
\end{aligned}
$$

Using the partial sum in (17) and the Adomian polynomials for the non-linear terms in (18), (14)-(16) yield (19)-(21). The final stage for the implementation of ADM is the coding of equations (19)-(21) in symbolic Mathematica software, which yields a very large symbolic solution.

$$
\begin{aligned}
& u(y)=\sum_{n=0}^{\infty} u_{n}(y), \quad w(y)=\sum_{n=0}^{\infty} w_{n}(y), \\
& \theta(y)=\sum_{n=0}^{\infty} \theta_{n}(y), \\
& \left.\begin{array}{l}
A_{n}=u^{2}: A_{0}=u_{0}^{2}, A_{1}=2 u_{0} u_{1}, A_{2}=u_{1}^{2}+2 u_{0} u_{2} \\
B_{n}=w^{2}: B_{0}=w_{0}^{2}, B_{1}=2 w_{0} w_{1}, B_{2}=w_{1}^{2}+2 w_{0} w_{2}
\end{array}\right\} . \\
& \sum_{n=0}^{r} u_{n}(y)=b_{1} y+\frac{b_{2}}{3 !} y^{3}- \\
& \int_{0}^{y} \int_{0}^{y} \int_{0}^{y} \int_{0}^{y}\left\{\begin{array}{l}
s \frac{d u}{d Y}-G-\frac{d^{2} u}{d Y^{2}}+ \\
\frac{M^{2}}{1+m^{2}}(u-m w)
\end{array}\right\} d Y d Y d Y d Y,
\end{aligned}
$$

$$
\begin{aligned}
& \sum_{n=0}^{r} w_{n}(y)=f_{1} y+\frac{f_{2}}{3 !} y^{3}- \\
& \int_{0}^{y} \int_{0}^{y} \int_{0}^{y} \int_{0}^{y}\left\{s \frac{d w}{d Y}-\frac{d^{2} w}{d Y^{2}}+\frac{M^{2}}{1+m^{2}}(w+m u)\right\} d Y d Y d Y d Y,
\end{aligned}
$$

$\sum_{n=0}^{r} \theta_{n}(y)=b_{3}+b_{4} y-$

$$
\int_{0}^{y} \int_{0}^{y}\left\{\begin{array}{l}
s \operatorname{Pr} \frac{d \theta}{d y}-B r\left(\frac{d u}{d y}\right)^{2}+\left(\frac{d w}{d y}\right)^{2}+ \\
a^{2}\left(\left(\frac{d^{2} u}{d y^{2}}\right)^{2}+\left(\frac{d^{2} w}{d y^{2}}\right)^{2}\right)+ \\
\lambda J\left(A_{n}+B_{n}\right)
\end{array}\right\} d Y d Y .
$$

\section{A. Results Verification}

The approximate solution obtained by ADM can be verified by comparing our result and the one in [44] as displayed in Table I.

\section{B. Entropy Generation Analysis}

The local entropy generation expression [35] for the flow is given as

$$
\begin{aligned}
& E_{G}=\frac{k}{T_{0}^{2}}\left(\frac{d T^{*}}{d y^{*}}\right)^{2}+\frac{\mu}{T_{0}}\left(\left(\frac{d u^{*}}{d y^{*}}\right)^{2}+\left(\frac{d w^{*}}{d y^{*}}\right)^{2}\right)+ \\
& \frac{\eta}{T_{0}}\left(\left(\frac{d^{2} u^{*}}{d y^{* 2}}\right)^{2}+\left(\frac{d^{2} w^{*}}{d y^{* 2}}\right)^{2}\right)+\lambda \frac{\sigma B_{0}^{2}}{T_{0} \rho v}\left(w^{* 2}+u^{* 2}\right)
\end{aligned}
$$

Using (9) in (22) yields

$$
\begin{aligned}
& N s=\left(\frac{d \theta}{d y}\right)^{2}+\frac{B r}{\Omega}\left(\left(\frac{d u}{d y}\right)^{2}+\left(\frac{d w}{d y}\right)^{2}\right)+ \\
& \frac{B r}{\Omega a^{2}}\left(\left(\frac{d^{2} u}{d y^{2}}\right)^{2}+\left(\frac{d^{2} w}{d y^{2}}\right)^{2}\right)+\frac{\lambda J h}{\Omega}\left(w^{2}+u^{2}\right)
\end{aligned}
$$
letting

Entropy generation within the flow can be analysed by

$$
\begin{aligned}
& N_{1}=\left(\frac{d \theta}{d y}\right)^{2}, N_{2}=\frac{B r}{\Omega}\left(\left(\frac{d u}{d y}\right)^{2}+\left(\frac{d w}{d y}\right)^{2}\right)+ \\
& \frac{B r}{\Omega a^{2}}\left(\left(\frac{d^{2} u}{d y^{2}}\right)^{2}+\left(\frac{d^{2} w}{d y^{2}}\right)^{2}\right)+\frac{\lambda J h}{\Omega}\left(w^{2}+u^{2}\right)
\end{aligned}
$$

If Bejan number $(\mathrm{Be})$ is less than one-half, irreversibility due to viscous dissipation dominates entropy generation and when $(B e)$ is greater than one-half irreversibility due to heat transfer dominates the fluid flow. Bejan number $(B e)$ equal to one-half indicates that both contribute equally to entropy generation. The Bejan number can be written as: 
$B e=\frac{N_{1}}{N_{s}}=\frac{1}{1+\Phi}, \Phi=\frac{N_{2}}{N_{1}}$.

TABLE I. RESULTS FOR VELOCITY PROFILES

\begin{tabular}{|c|c|c|c|}
\hline \multicolumn{2}{|c|}{$\mathbf{G}=\mathbf{1}, \mathbf{s}=\mathbf{0 . 1}, \boldsymbol{\alpha}=\mathbf{1}, \mathbf{M}=\mathbf{0}$} & \multicolumn{2}{|c|}{$[\mathbf{4 4}]$} \\
\hline $\mathbf{S} / \mathbf{N}$ & $\mathbf{U}_{\text {ADM }}$ & $\mathbf{U}_{\text {EXACT }}$ & $\mathbf{U}_{\text {ADM }}$ \\
\hline 0 & 0 & $-3.91321 \times 10^{-14}$ & 0 \\
\hline 0.1 & 0.003714182 & 0.00371418 & 0.00371418 \\
\hline 0.2 & 0.007024039 & 0.00702404 & 0.00702404 \\
\hline 0.3 & 0.009612623 & 0.00961262 & 0.00961262 \\
\hline 0.4 & 0.011255559 & 0.0112556 & 0.0112556 \\
\hline 0.5 & 0.011818879 & 0.0118189 & 0.0118189 \\
\hline 0.6 & 0.011257781 & 0.0112578 & 0.0112578 \\
\hline 0.7 & 0.009616293 & 0.00961629 & 0.00961629 \\
\hline 0.8 & 0.007027825 & 0.00702782 & 0.00702783 \\
\hline 0.9 & 0.003716603 & 0.0037166 & 0.0037166 \\
\hline 1 & $2.202672 \times 10^{-11}$ & $-3.91321 \times 10^{-14}$ & $-7.66586 \times 10^{-18}$ \\
\hline
\end{tabular}

TABLE II. RESULTS (EXACT SOLUTION) FOR VELOCITY PROFILES $\mathrm{G}=1, \mathrm{~S}=0.1, \mathrm{~A}=1, \mathrm{M}=0$

\begin{tabular}{|c|c|c|c|}
\hline $\mathbf{S} / \mathbf{N}$ & $\mathbf{U}_{\text {EXACT }}$ & $\mathbf{U}_{\text {ADM }}$ & \\
\hline 0 & $6.94 \mathrm{E}-15$ & 0 & $6.94 \mathrm{E}-15$ \\
\hline 0.1 & 0.003714182 & 0.00371418 & $1.20 \mathrm{E}-12$ \\
\hline 0.2 & 0.007024039 & 0.00702404 & $2.22 \mathrm{E}-12$ \\
\hline 0.3 & 0.009612623 & 0.00961262 & $2.91 \mathrm{E}-12$ \\
\hline 0.4 & 0.011255559 & 0.01125556 & $3.05 \mathrm{E}-12$ \\
\hline 0.5 & 0.011818879 & 0.01181888 & $2.44 \mathrm{E}-12$ \\
\hline 0.6 & 0.011257781 & 0.01125778 & $8.78 \mathrm{E}-13$ \\
\hline 0.7 & 0.009616293 & 0.00961629 & $1.87 \mathrm{E}-12$ \\
\hline 0.8 & 0.007027825 & 0.00702782 & $6.13 \mathrm{E}-12$ \\
\hline 0.9 & 0.003716603 & 0.0037166 & $1.22 \mathrm{E}-11$ \\
\hline 1 & $9.98 \mathrm{E}-15$ & $2.0267 \mathrm{E}-11$ & $2.03 \mathrm{E}-11$ \\
\hline
\end{tabular}

\section{RESULTS AND DISCUSSION}

This section presents results of the analysis as plots in Figures $1-13$ by fixing parameters $P r=0.71, m=0.5, J h=2, G=1$, $B r=0.5$. To explain the effect of Hall current $(m)$, Joule heating $(J)$, suction/injection $(s)$ and magnetic $(M)$ parameters on velocity profile, the non-dimensional velocity $u$ and $w$ against $y$ is presented in Figures 1 to 3. Figures 1(a) and 1(b) illustrate the influence of Hall current on fluid velocity. It is apparent from these figures that fluid motion is enhanced as hall current increases. This is due to the fact that Hall current reduces the effect of the Lorentz resistive force imposed by the applied magnetic field on fluid motion. Figures 2(a) and 2(b) demonstrate that fluid motion accelerates at the lower wall, the trend is reversed at the upper wall with injection as suction/injection parameter $(s>0)$ increases, this indicates a shift in flow symmetry.

In Figures 3(a) and 3(b), magnetic effect on fluid velocity is displayed. We can see that fluid motion is inhibited, this is due to the fact that application of transverse magnetic field usually generates a resistive type of force called Lorentz force that retards fluid flow. The response of temperature profile to the variation in Hall parameter, Joule heating and magnetic parameter is depicted in Figures 4-6. In Figure 4, fluid temperature is reduced for different values of Hall parameter, however Hall current does not have much significant effect on fluid temperature.

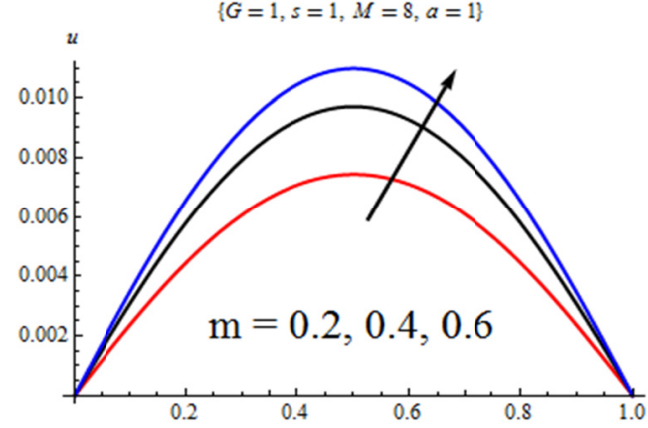

(a)

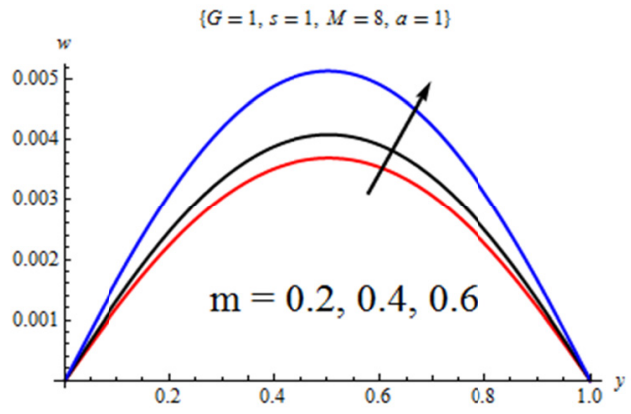

(b)

Fig. 1. (a) Primary velocity profile and (b) Secondary velocity profile, for different $m$

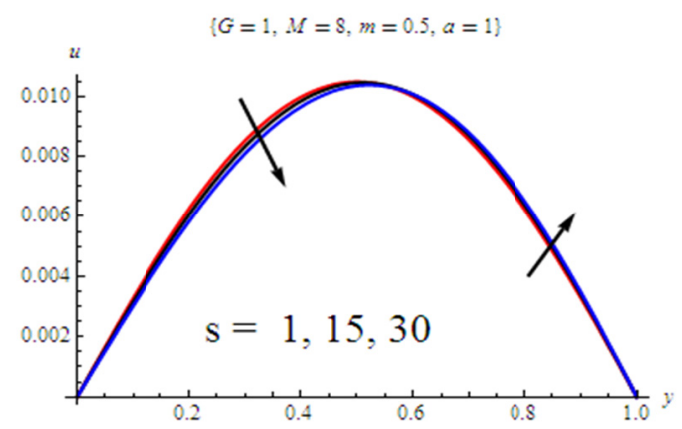

(a)

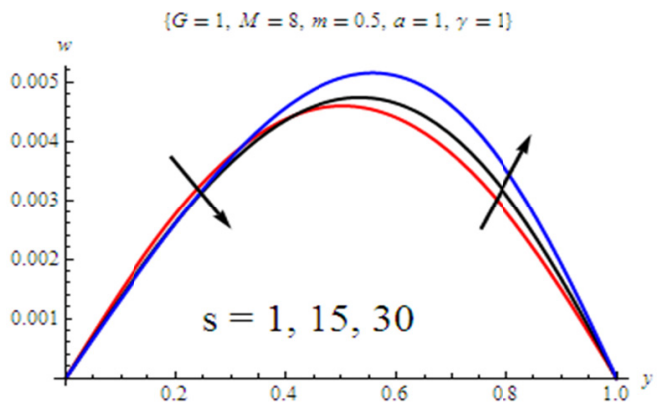

(b)

Fig. 2. (a): Primary velocity profile and (b) Secondary velocity profiles for for different $\mathrm{s}$ 


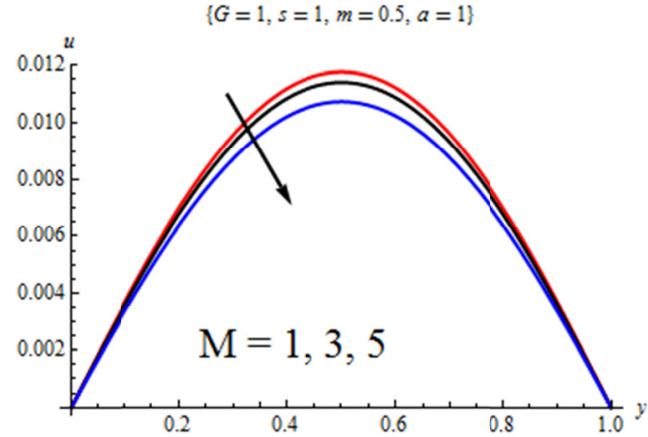

(a)

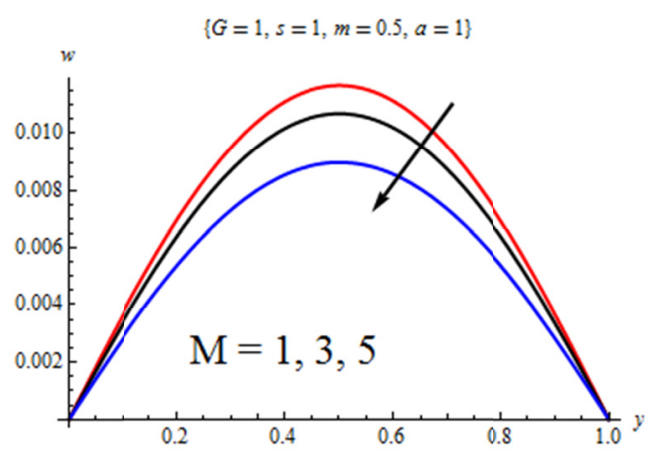

(b)

Fig. 3. (a) Primary velocity profile and (b) Secondary velocity profile for different $\mathrm{M}$

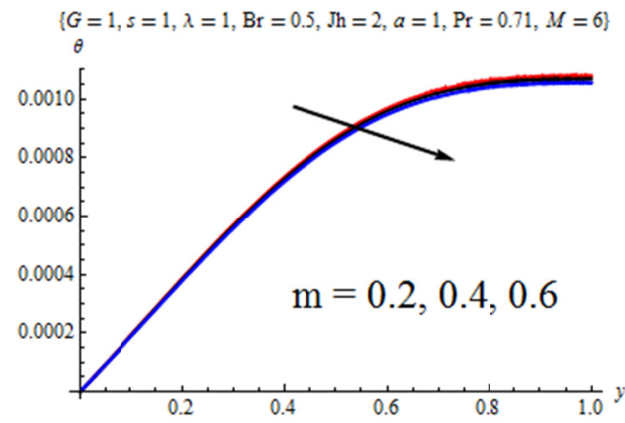

Fig. 4. Temperature profile for different $m$

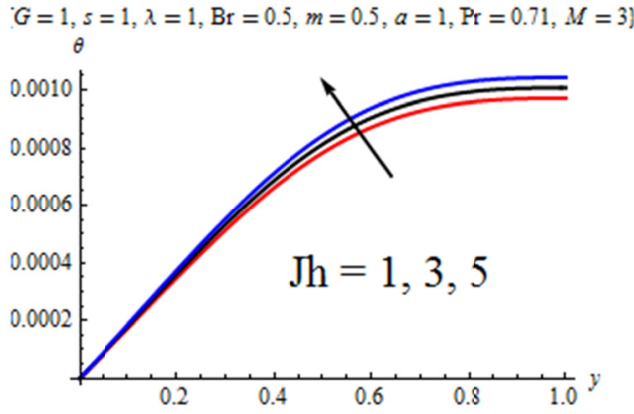

Fig. 5. Temperature profile for different J

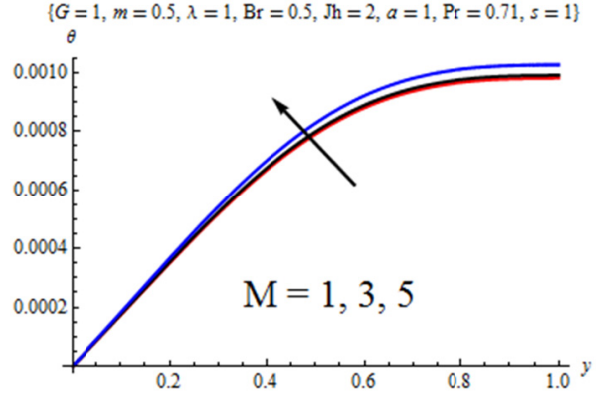

Fig. 6. Temperature profile for different $\mathrm{M}$

Figure 5 demonstrates that fluid temperature rises with increase in the Joule heating parameter. Figure 6 depicts the effect of varying values of magnetic field parameter on fluid temperature. It is observed that temperature is enhanced as magnetic field increases, due to the increase in fluid viscous heating which enhances transfer of heat to the boundaries. Figures 7-9 represent the influence of Hall current, Joule heating and suction/injection parameters on the entropy generation. Entropy generation is enhanced with the increase in Hall current and Joule heating parameters as depicted in Figures 7-8. Joule heating is the product of Brinkman number and Hartman number, increase in the parameters result in the corresponding rise in entropy generation. In Figure 9, increase in suction/injection parameter retards fluid flow at plate $\mathrm{y}=0$ while opposite trend is observed at plate $y=1$. This phenomenon is attributed to the change in flow symmetry reported in Figures $2 \mathrm{a}$ and $2 \mathrm{~b}$.

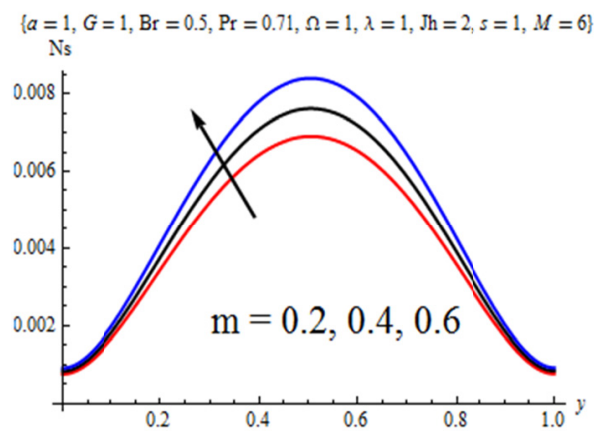

Fig. 7. Entropy generation for different $\mathrm{m}$

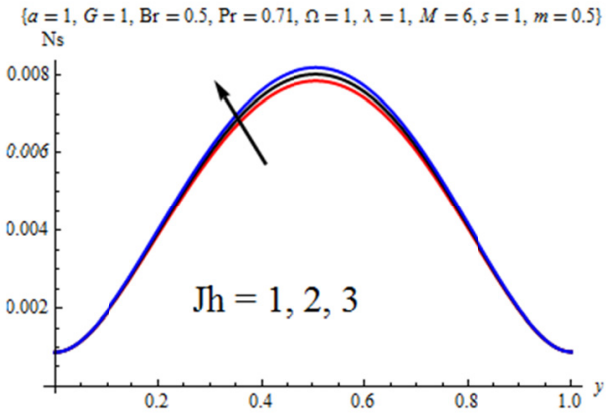

Fig. 8. Entropy generation for different $\mathrm{J}$ 
Finally, the influence of Hall current, Joule heating, suction/injection and magnetic parameters on Bejan number are displayed in Figures 10-13. Figures 10 and 13 reveal that Bejan number reduces as the values of Hall current and suction/injection parameters vary while the trend is reversed as Joule heating and magnetic parameters increase. It is concluded that both viscous dissipation and heat transfer contribute to entropy generation.

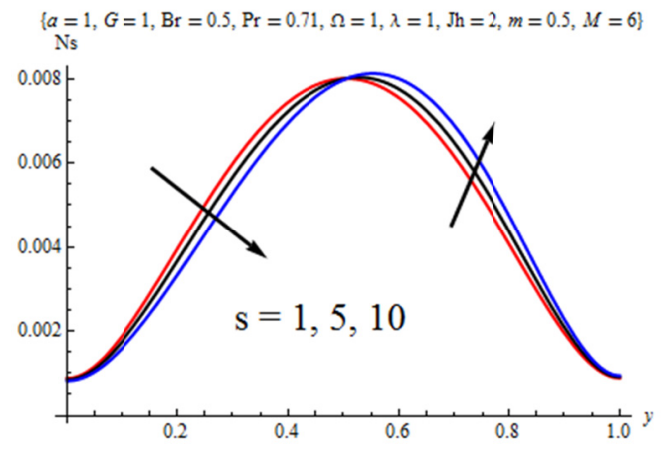

Fig. 9. Entropy generation profile for different $s$

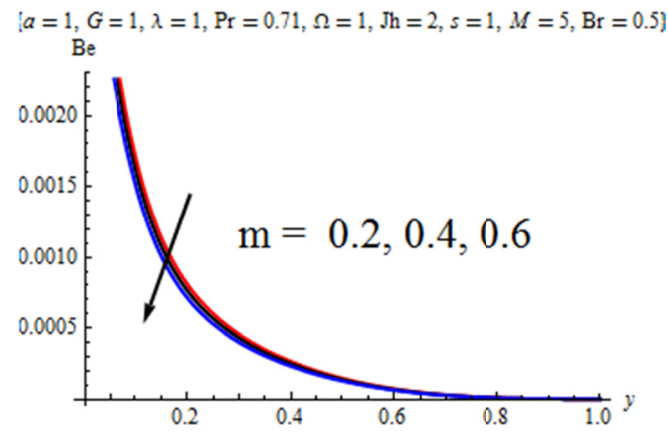

Fig. 10. Bejan number for different $\mathrm{m}$

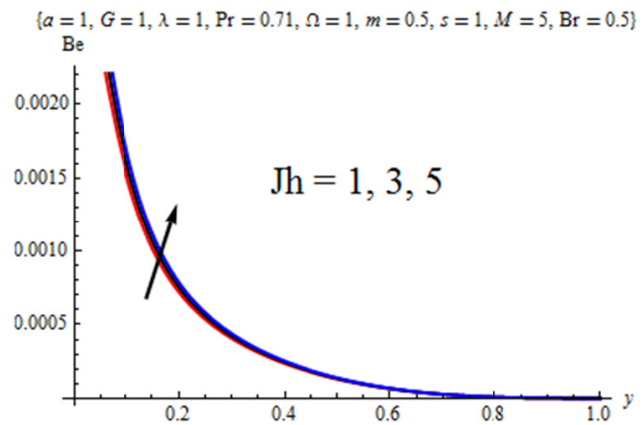

Fig. 11. Bejan number for different $\mathrm{J}$

\section{CONCLUSION}

An analytical investigation of the effects of hall current and Joule heating on entropy generation of a couple stress fluid has been conducted. The governing equations were obtained, nondimensionalised and solved using Adomian decomposition technique. The solution obtained is used to compute entropy generation and irreversibility ratio. Plots are presented to explain the physics of the flow.

From the results it is concluded that:

- Hall current increases fluid velocity and entropy generation while the temperature and Bejan number are reduced.

- Increase in Joule heating parameter enhances fluid temperature, entropy generation and Bejan number.

- Hartman number retards fluid flow, increases fluid temperature and Bejan number.

- Both viscous dissipation and heat transfer contributes to entropy generation.

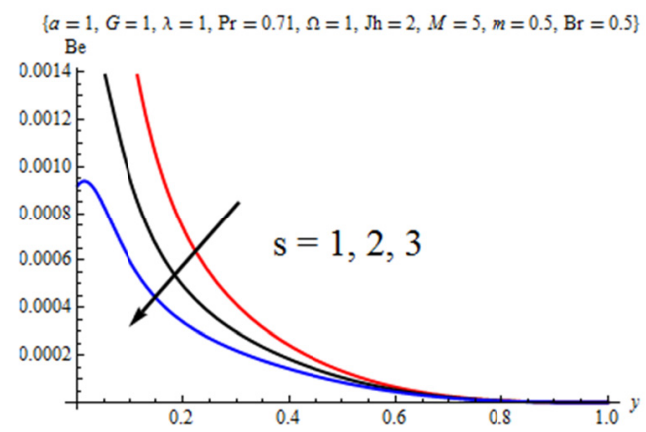

Fig. 12. Bejan number for different $\mathrm{s}$

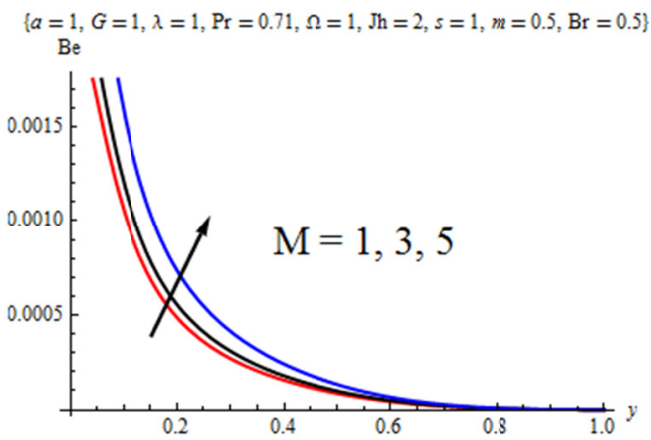

Fig. 13. Bejan number for different $\mathrm{M}$

NOMENCLATURE

\begin{tabular}{|c|c|}
\hline $\mathrm{u}^{\prime}$ & velocity component along $\mathrm{x}$-axis \\
\hline $\mathrm{w}^{\prime}$ & velocity component along $\mathrm{y}$-axis \\
\hline$\mu$ & dynamic viscosity \\
\hline $\mathrm{p}$ & fluid pressure \\
\hline $\mathrm{T}^{\prime}$ & fluid temperature \\
\hline $\mathrm{T}_{0}$ & initial fluid temperature \\
\hline $\mathrm{k}$ & thermal conductivity of the fluid \\
\hline $\mathrm{Br}$ & Brinkman number \\
\hline $\mathrm{G}$ & dimensionless pressure gradient \\
\hline$\theta$ & dimensionless temperature \\
\hline $\mathrm{u}, \mathrm{w}$ & the dimensionless velocities \\
\hline $\mathrm{v}_{0}$ & constant velocity of fluid suction/injection \\
\hline $\mathrm{s}$ & suction/injection parameter \\
\hline
\end{tabular}




\begin{tabular}{|c|c|}
\hline & $(\mathrm{s}>0$ is suction and $\mathrm{s}<0$ is injection $)$ \\
\hline $\mathrm{v}$ & kinematic viscosity \\
\hline $\mathrm{N}_{\mathrm{S}}$ & dimensionless entropy generation rate \\
\hline $\mathrm{Be}$ & Bejan number \\
\hline $\mathrm{E}_{\mathrm{G}}$ & entropy generation parameter \\
\hline$\Omega$ & temperature difference parameter \\
\hline $\mathrm{C}_{\mathrm{p}}$ & specific heat at constant pressure \\
\hline$\eta$ & channel width \\
\hline $\mathrm{h}$ & fluid density \\
\hline$\rho$ & uniform transverse magnetic field \\
\hline $\mathrm{B}_{0}$ & magnetic field parameter \\
\hline $\mathrm{M}$ & Joule heating parameter \\
\hline $\mathrm{Jh}$ & couple stress parameter \\
\hline $\mathrm{a}$ & Prandtl number \\
\hline $\mathrm{Pr}$ & Hall current parameter \\
\hline $\mathrm{m}$ &
\end{tabular}

\section{REFERENCES}

[1] G. K. Batchelor, "On the spontaneous magnetic field in a conducting liquid in turbulent motion", Proceedings of the Royal Society of London. Series A, Mathematical and Physical Sciences, Vol. 21, No. 1066, pp. 406-416, 1950

[2] J. C. R. Hunt, J. A. Shercliff, "Magnetohydrodynamics at high Hartmann number", Annual Review of Fluid Mechanics, Vol. 3, pp. 37-62, 1971

[3] S. Gupta, "Magnetohydrodynamic Ekmann layer", Acta Mechanica, Vol. 13, pp. 155-160, 1972

[4] D. R. V. Prasada Rao, D. V. Krishna, L. Debnath, "Combined effect of free and forced convection on MHD flow in a rotating porous channel", International Journal of Mathematics and Mathematical Sciences, Vol. 5, No. 1, pp. 165-182, 1982

[5] J. A. Gbadeyan, A. S. Idowu, "Radiation effect of magnetohydrodynamic flow of gas between concentric spheres", Journal of the Nigerian Association of Mathematical Physics, Vol. 10, pp. 305-314, 2006

[6] O. Areo, P. O. Olaleye, J. A. Gbadeyan, "The radiative effect on velocity, magnetic and temperature fields of a magneto hydrodynamic oscillatory flow past a limiting surface with variable suction", European Journal of Applied Sciences, Vol. 3, No. 3, pp. 102-112, 2011

[7] S. O. Adesanya, E. O. Oluwadare, J. A. Falade, O. D. Makinde, "Hydromagnetic natural convection flow between vertical parallel plates with time-periodic boundary conditions", Journal of Magnetism and Magnetic Materials, Vol. 396, pp. 295-303, 2015

[8] I. Olajuwon, "Convection heat and mass transferr in a hydromagnetic flow of second grade fluid in the presence of thermal radiation and thermal diffusion", International Communications in Heat and Mass Transfer, Vol. 38, No. 3, pp. 377-382, 2011

[9] Raptis, P. C. Ram, "Effects of hall current and rotation","Astrophysics and Space Science, Vol. 106, No. 2, pp. 257-264, 1984

[10] M. Abd El-Aziz1, T. Nabil, "Homotopy analysis solution of hydromagnetic mixed convection flow past an exponentially stretching sheet with hall current", Mathematical Problems in Engineering, Vol. 2012, Article ID 454023, 2012

[11] S. Das, S. L. Maji, R. N. Jana, "Hall Effects on unsteady hydromagnetic flow induced by a porous plate", International Journal of Computer Applications (0975 - 8887), Vol. 57, No. 18, pp. $37-44,2012$

[12] K. Jha, C. A. Apere, "Combined effect of hall and ion-slip currents on unsteady MHD Couette flows in a rotating system", Journal of the Physical Society of Japan, Vol. 79, No. 10, 2010
[13] Pal, B. Talukdar, I. S. Shivakumara, K. Vajravelu, "Effects of Hall current and chemical reaction on oscillatory mixed convectionradiation of a micropolar fluid in a rotating system", Chemical Engineering Communications, Vol. 199, pp. 943-965, 2012

[14] S. Asghar, M. R. Mohyuddin, T. Hayat, "Effects of Hall current and heat transfer on flow due to a pull of ecentric rotating disks", International Journal of Heat and Mass Transfer, Vol. 48, No. 3-4, pp. 599-607, 2005

[15] M. Aboeldahab, E. M. E. Elbarbary, "Hall current effect on magnetohydrodynamic free convection flow past a semi-infinite vertical plate with mass transfer", International Journal of Engineering Science, Vol. 39, No. 14, pp, 1641-1652, 2001

[16] Arikoglu, I. Ozkol, G. Komurgoz, "Effect of slip on entropy generation in a single rotating disk in MHD flow", Applied Energy, Vol. 85, No. 12, pp. 1225-1236, 2008

[17] M. M. Rashidi, N. Freidooni Mehr, "Effects of velocity slip and temperature jump on the entropy generation in MHD flow over a porous rotating disk", Journal of Mechanical Engineering, Vol. 1, No. 3, pp. 3-14. 2012

[18] M. M. Rashidi, M. M. Bhatti, M. A. Abbas, M. E. Ali, "Entropy generation on MHD blood flow of nanofluid due to peristaltic waves", Entropy, Vol. 18, No. 4, 2016

[19] S. O. Adesanya, J. A. Falade, "Thermodynamics analysis of hydromagnetic third grade fluid flow through a channel filled with porous medium", Alexandria Engineering Journal, Vol. 54, No. 3, pp. 615-622, 2015

[20] A. Opanuga, J. A. Gbadeyan, S. A. Iyase, H. I. Okagbue, "Effect of thermal radiation on entropy generation of hydromagnetic flow through porous channel", Pacific Journal of Science and Technology, Vol. 17, No. 2, pp. 59-68, 2016

[21] S. O. Adesanya, J. A. Falade, S. Jangili, O. A Beg, "Irreversibility analysis for reactive third-grade fluid flow and heat transfer with convective wall cooling", Alexandria Engineering Journal, Vol. 56, No. 1, pp. 153-160, 2017

[22] S. O. Adesanya, O. D. Makinde, "Irreversibility analysis in a couple stress film flow along an inclined heated plate with adiabatic free surface", Physica A, Vol. 432, pp. 222-229, 2015

[23] A. Opanuga, H. I. Okagbue, O. O. Agboola, "Irreversibility analysis of a radiative MHD Poiseuille flow through porous medium with slip condition", Proceedings of the World Congress on Engineering, London, UK, Vol. 1, pp. 167-171, July 5-7, 2017

[24] M. Pakdemirli, B. S. Yilbas, "Entropy generation in a pipe due to non-Newtonian fluid flow: Constant viscosity case", Sadhana, Vol. 31, No. 1, pp. 21-29, 2006

[25] A. Opanuga, H. I. Okagbue, O. O. Agboola, O. F. Imaga, "Entropy generation analysis of buoyancy effect on hydromagnetic poiseuille flow with internal heat generation", Defect and Diffusion, Vol. 378, pp. 102-112, 2017

[26] L. B. Erbay, Z. Altac, B. Sulus, "An analysis of the entropy generation in a square enclosure”, Entropy, Vol. 5, No. 5, pp. 496505,2003

[27] A. Opanuga, E. A. Owoloko, O. O. Agboola, H. I. Okagbue, "Application of homotopy perturbation and modified Adomian decomposition methods for higher order boundary value problems", Proceedings of the World Congress on Engineering, London, UK, Vol. 1, July 5-7, 2017

[28] M. C. Agarana, M. E. Emetere, "Solving non-linear damped driven simple pendulum with small amplitude using a semi analytical method", ARPN Journal of Engineering and Applied Sciences, Vol. 11, No. 7, pp. 4478-4484, 2016

[29] M. C. Agarana, A. N. Ede, "Application of differential transform method to vibration analysis of damped railway bridge on Pasternak foundation under moving train", Proceedings of The World Congress on Engineering and Computer Science 2016, London, UK, June 29-July 1, 2016, 2016

[30] O. O. Agboola, J. A. Gbadeyan, A. A. Opanuga, M. C. Agarana, S. A. Bishop, J. G. Oghonyon, "Variational Iteration Method for Natural Frequencies of a Cantilever Beam with Special Attention 
to the Higher Modes", Proceedings of The World Congress on Engineering and Computer Science 2017, London, UK, July 5-7, 2017

[31] A. A. Opanuga, E. A. Owoloko, H. I. Okagbue, O. O. Agboola, "Finite difference method and Laplace transform for boundary value problems", Proceedings of The World Congress on Engineering and Computer Science 2017, London, UK, July 5-7, 2017

[32] V. Daftardar-Gejj H. Jafari, "Solving a multi-order fractional differential equation using Adomian Decomposition", Applied Mathematics and Computation, Vol. 189, No. 1, pp. 541-548, 2007

[33] A. M. Wazwaz, "Analytical solution for the time-dependent Emden-Fowler type of equations by Adomian decomposition method", Applied Mathematics and Computation, Vol. 166, No. 3, pp. $638-651,2005$

[34] K.Haldar, "Application of Adomian's approximations to the Navier-Stokes equations in cylindrical coordinates", Applied Mathematics Letters, Vol. 9, No. 4, pp. 109-113, 1996

[35] B. Zhang, Q.-B. Wu, X.-G. Luo, "Experimentation with two-step Adomian decomposition method to solve evolution models", Applied Mathematics and Computation, Vol. 175, No. 2, pp. 14951502,2006

[36] A. M. Wazwaz, "Padé approximants and Adomian decomposition method for solving the Flierl-Petviashivili equation and its variants", Applied Mathematics and Computation, Vol. 182, No. 2, pp. 1812-1818, 2006

[37] H. Haddadpour, "An exact solution for variable coefficients fourthorder wave equation using the Adomian method", Mathematical and Computer Modelling, Vol. 44, No. 11-12, pp. 1144-1152, 2006

[38] S.Nadeem, N. S. Akbar, "Effects of heat transfer on the peristaltic transport of MHD Newtonian fluid with variable viscosity: Application of Adomian decomposition method", Communications in Nonlinear Science and Numerical Simulation, Vol. 14, No. 11, pp. 3844-3855, 2009

[39] M. Tataria, M. Dehghana, M. Razzaghi, "Application of the Adomian decomposition method for the Fokker-Planck equation", Mathematical and Computer Modelling, Vol. 45, No. 5-6, pp. 639650,2007

[40] S. O. Adesanya, E. S. Babadipe, S.A. Arekete, "A new result on Adomian decomposition method for solving Bratu's problem", Mathematical Theory and modeling, Vol. 3, No. 2, pp. 116-120, 2013

[41] T. G. Cowling, Magnetohydrodynamics, Interscience, Inc, New York, 1957

[42] R. C. Meyer, "On Reducing Aerodynamic Heat-Transfer Rates by MagnetohydrodynamicTechniques", Journal of the Aerospace Sciences, Vol. 25, No. 9, pp. 561-566, 1958

[43] S. Das, R. N. Jana, "Effects of hall current on entropy generation in a porous channel with suction/injection", International Journal of Energy \& Technology, Vol. 5, No. 25, pp. 1-11, 2013

[44] S. O. Adesanya, O. D. Makinde, "Effects of couple stresses on entropy generation rate in a porous channel with convective heating", Computational and Applied Mathematics, Vol. 34, No. 1, pp. 293-307, 2015

[45] A. Bejan, Entropy Generation through Heat and Fluid Flow, Wiley, New York, 1982 